\title{
ВMJ Global Health Is time running out? The urgent need for appropriate global health curricula in Germany
}

\author{
Angela Schuster (D) ,' Nora Anton, ${ }^{2}$ Pascal Grosse,,${ }^{3,4}$ Christoph Heintze ${ }^{1}$
}

\begin{abstract}
To cite: Schuster A, Anton N, Grosse P, et al. Is time running out? The urgent need for appropriate global health curricula in Germany. BMJ Global Health 2020;5:e003362. doi:10.1136/ bmjgh-2020-003362
\end{abstract}

Handling editor Seye Abimbola

Received 6 July 2020

Revised 21 0ctober 2020

Accepted 23 October 2020

Check for updates

(C) Author(s) (or their employer(s)) 2020. Re-use permitted under CC BY-NC. No commercial re-use. See rights and permissions. Published by BMJ.

${ }^{1}$ Insitute of General Practice, Charité-Universitätsmedizin Berlin, Freie Universität Berlin, Humboldt-Universität zu Berlin and Berlin Institute of Health, Berlin, Germany

${ }^{2}$ Charité Global Health, Charité-Universitätsmedizin Berlin, Freie Universität Berlin, Humboldt-Universität zu Berlin and Berlin Institute of Health,

Berlin, Germany

${ }^{3}$ Dean of education office, Charité-Universitätsmedizin Berlin, Freie Universität Berlin, Humboldt-Universität zu Berlin and Berlin Institute of Health, Berlin, Germany

${ }^{4}$ Department of Neurology, Charité-Universitätsmedizin Berlin, Freie Universität Berlin, Humboldt-Universität zu Berlin and Berlin Institute of Health, Berlin, Germany

Correspondence to

Dr Angela Schuster:

angela.schuster@charite.de

\section{ABSTRACT}

Recently, representatives of politics, health officials and academia in Germany have advocated a greater role for Germany in matters concerning global health. However, health professionals in Germany are rarely taught about global health topics and accordingly real expertise in this field is lacking. To advance knowledge and competencies at German universities and adequately equip health professionals to achieve Germany's political goals, global health curricula must be developed at medical schools and other institutions. Such ambitions raise questions about the required content and dimensions of global health curricula as the field is currently highly heterogeneous and ill defined. To systematically identify strengths and shortcomings of current curricula, we scrutinised the global health curriculum at our institution, CharitéUniversitätsmedizin Berlin, using an analytical framework that integrates the various approaches of global health. Our analysis identified that four (technical, social justice, security and humanitarian) of five approaches are present in our core global health curriculum. Local and global aspects of the field are equally represented. We propose that the use of such a structured analytical framework can support the development of GH curricula for all health professionals-in Germany and elsewhere. But it can also help to evaluate existing curricula like ours at Charité. This framework has the potential to support the design of comprehensive GH trainings, serving German aspirations in politics and academia to promote health worldwide.

\section{INTRODUCTION}

In 2019, the British Medical Journal published an article which announced 'a new global health strategy for Germany'. ${ }^{1}$ The political implications of this article are quite explicit with the engagement of German institutions in the field of global health as an extension of 'Germany's unwavering support for multilateralism' as expressed in the subtitle. The three authors, representing the Graduate Institute of International and Development Studies in Geneva and the Wellcome Trust in both London and Berlin, seek a future leadership role for Germany in global health in the areas of epidemic preparedness and antimicrobial resistance. However, to achieve

\section{Summary box}

Progress in global health is hampered by an increasing polarisation into a world that seems to be divided into multilateral vs nationalistic political practices.

- Political leaders in Germany have advocated for a leading role of German institutions while in German academia an appropriate global health education for tomorrow's global health professionals is still lacking.

- We developed a framework based on merging existing categorical schemes into one common analytical framework in order to clarify key approaches and to provide a simple structure for the development of global health education.

- The proposed framework can be used to evaluate existing global health curricula to guide the steering process towards a balanced equilibrium of approaches and actors.

such international leadership requires 'developing stronger domestic global health infrastructure'. Kickbusch et al argue that global health matters have been gaining substantial momentum in Germany, supported by the current government in the political arena, while the structural and intellectual basis for these aspirations requires substantial development.

Certainly, one major driving force to advance global health in German politics was the institution of the World Health Summit (WHS) in Berlin starting in 2009 at the occasion of the 300th anniversary of our institution, Charité-Universitätsmedizin Berlin (Charité). Supported by the German government among others, the WHS has developed into a prototypical representation of multilateral global health diplomacy in the international political sphere. In parallel, medical students and teachers of global health have organised bottom up initiatives such as the Global Health Alliance Deutschland which has led to a stronger endorsement of global health issues in their respective academic 
institutions. Universities with a traditionally stronger focus on tropical medicine, such as Heidelberg University have enlarged their scope; others such as Bielefeld University have developed their global health competences based on their expertise in the field of public health.

Further new challenges such as emerging pathogens, the worldwide increase of refugees or climate change have transformed the field of global health into a paramount aspect of official German politics (see, eg, coalition agreement of the governing parties 2018, p102²).

Thus, if Germany designates global health as a cardinal focus of their multilateral politics, refuting the alternative nationalistic approach to health, it is necessary to expand knowledge and competencies in global health among health professionals in Germany. Such aspirations are complex, in particular because of structural peculiarities in medical schools and interpretations as to what global health should represent. Further, the principle of academic freedom that allows researchers to teach or research every topic according to their individual interests, can be a barrier for introducing global health content as a cross sectional topic across distinct medical disciplines.

In the following, we describe the process of how we managed to install a global health curriculum into an already existing medical curriculum. We present an analysis of our global health curriculum using a multidimensional framework to assess in retrospect whether our curriculum complies with the demands articulated by Kickbusch et al. ${ }^{1}$ Such a framework captures the multifaceted aspects of global health and serves as a template to analyse other global health curricula. To the best of our knowledge, such an analytical approach focussing on the analysis of medical curricula is the first of its kind in Germany. We believe that our insights add to the current discourse on global health education worldwide from the perspective of a medical university in a high-income country with an increasing academic engagement in this area.

\section{WHAT IS SPECIFIC TO GLOBAL HEALTH CURRICULA?}

Starting in 2015 our intention to implement a global health curriculum was driven by our individual professional experiences with global health as well as by the demands of our students. Students' expected an increased presence of global health in their curriculum, as supported by the results of a national survey on the state of global health in Germany regarding education and research. ${ }^{3}$ This survey concluded that matters concerning global health are weak in Germany except for a few universities with a tradition in tropical medicine. The challenge at Charité was to introduce a global health component into an existing medical curriculum that had gradually become modularised. To insert an interdisciplinary field like global health into an existing medical curriculum, structural, academic and historical considerations have to be taken into account.

First, medical schools traditionally consist of big clinical departments, complemented by basic science institutes and a few departments related to the humanities and the social sciences. Such an asymmetrical setting represents the matrix in which cross-sectional fields such as global health are embedded. Global health has implications for most, if not all clinical and theoretical disciplines. In high-income countries only a few representatives of clinical disciplines show a specific interest or have specialised training in global health matters. More often, global health in high-income countries is confined to the realm of public health and separated from clinical medicine. To date, only a few academic health institutions have designated global health centres, mostly in the Anglo-Saxon world. $^{4}$

Second, the medical education community has achieved minimal consensus about which topics should be integrated into global health curricula, a state of affairs that is reflected by divergent curricular offerings in global health institutions. ${ }^{5-9}$ The discrepancy between aspirations and reality is not surprising as there is no accepted definition of global health. Instead, differing and sometimes contradictory concepts shape the field. ${ }^{10}$ To date, differing concepts of global health carry the risk of being arbitrarily used and tailored according to the needs of its users. ${ }^{11}$ Further, the role of informal or hidden curricula as defined by interpersonal relations, institutional rules and culture in global health education reduce transparency and complicate the measurement of educational outcomes. ${ }^{12}$ In Europe, including Germany, various institutions have attempted to shape competency-based frameworks for global health education. ${ }^{13} 14$ However, these efforts are often conceived as separate curricula that are not considered to be suitable for the integration in already existing medical curricula.

Lastly, some of Germany's historical peculiarities shape global health as an academic discipline along the boundaries of international health, public health and tropical medicine. ${ }^{15}$ The racist misuse of public health politics during National Socialism ${ }^{16}$ caused population health sciences to fall into disrepute for many decades after World War II. ${ }^{17}$ Thus, population health has only recently been fostered in German academia. Additionally, what is called global health today has its historical roots in the European and US-colonialism of the 18th century with its inherent asymmetrical power relations between colonisers and colonised. Tropical medicine of the 19th and 20th century extended such asymmetrical power relations into the field of medicine that modern concepts of global health must overcome. Tropical medicine was a strong field in Germany before World War I, but was in limbo once its original field of activity was hampered by the loss of German colonies after the World War I. This disrupted the transition from colonial medicine to global health in Germany compared with other colonial powers 
such as for example, the UK, France, the Netherlands, or Belgium.

\section{CATEGORIES FOR THE ANALYSIS OF OUR CURRICULUM}

We identified global health contents based on the understanding of global health as an umbrella term, ${ }^{15}$ that allowed the inclusion of a broad variety of global health classes. We opted for the looser umbrella concept instead of a normative definition of global health because the umbrella concept is more inclusive and more comprehensive.

To analyse the medical curriculum we undertook the following steps. First, to capture the multifaceted cross-sectional aspects of our curriculum, we identified three different categories for analysis through a scoping literature review. To assess the first category, the target group of our curricular offerings we used the framework of Havemann and Bösner. ${ }^{15}$ The authors distinguish between students with no special interest in global health, who can convey basic knowledge through a core curriculum; interested students that deepen their knowledge in elective courses, and passionate global health students aiming to pursue a global health career and engage in postgraduate global health courses.

Our second category, the global health approach, classifies global health approaches in academia and politics using the frameworks of Cole et $a l^{18}$ and Labonté and Gagnon. ${ }^{10}$ Cole et al developed a conceptual framework to analyse global health activities based on the idea that the underlying rationale and the implications for global health activities are often lacking at schools for public health. ${ }^{18}$ To counter such shortcomings, the authors subdivide global health activities in research and education into technical, humanitarian, entrepreneurial and social justice approaches. While Cole $e t a l^{18}$ developed their model in an academic setting, Labonté and Gagnon ${ }^{10}$ analysed global health discourses from the perspective of foreign politics. In their view, global health is an arena that encompasses international diplomacy, health security, development cooperation, human rights, and ethical reasoning, among other areas. ${ }^{10} 19$ In our analysis, we matched Cole's approaches with Labonté's policy frames, then we identified the categories relevant for global health education in medical curricula. In box 1, we display the global health approaches of our framework along with their respective guiding principles and agents for implementation.

The third category of our analysis differentiates the local, glo-cal and global focal point based on Bozorgmehr's interpretation of the term global. ${ }^{14}$ Bozorgmehr distinguishes between a regional or national local level, (='local focus' in our framework), a transterritorial level (='glo-cal focus' in our framework) taking health issues in foreign counties into account, and, finally, a supraterritorial level that focusses on social, political, economic and cultural links anywhere in the world (='global focus' in our framework). ${ }^{14}$ Figure 1 shows how the existing
Box 1 Global health approaches for the analytical framework (adapted from Cole et $a l^{18}$ Labonté and Gagnon $\left.{ }^{10}\right)^{*}$

Security approach

- Guiding principle is the protection of health with a focus on economic and national security.

- Implementation through cooperation with state actors and the military; focus on emergency preparedness within national states or unions of states and on prevention of outbreaks outside previously set boundaries.

- Education focusing on health protection locally and on epidemics containment globally.

\section{Entrepreneurial approach}

- Guiding principle is the promotion of innovation, including the procurement of necessary resources and the assumption of possible risks.

- Implementation through public-private partnerships. Production and distribution of funds by market-based mechanisms. Frequent focus on new technologies and digitalisation.

- Education focusing on multidisciplinary courses on innovation in the health sector.

\section{Technical approach}

- Guiding principle is steering to improved health through scientific and technological improvements.

- Implementation of surveillance, disease prevention and guideline development in cooperation with supranational actors.

- Education focusing on technical, scientific and epidemiological competences to solve problems in order to understand and respond to substantive public health problems of lower and middle income countries (LMIC).

\section{Humanitarian approach}

- Guiding principle is to alleviate suffering and save lives based on charity and philanthropy.

- Implementation in large-scale emergencies, disasters or crises in cooperation with international non-state actors and humanitarian NGOs.

- Education focusing on disaster management and humanitarian aid.

Social justice approach

- Guiding principle is a critical global health ethic, solidarity and human rights.

- Implementation in analyses of macroeconomic and trade policies and their consequences for health. Targeted horizontal cooperation with civil society and state actors in structurally weaker countries and promotion of health systems strengthening.

- Education focusing on social justice, human rights and global health ethics.

*Verbatim quotes of the original sources are marked in italic.

frameworks were merged into one comprehensive tool for analysis.

\section{THE GLOBAL HEALTH CURRICULUM AT THE MEDICAL SCHOOL OF CHARITÉ}

Global health topics were identified in the mandatory core curriculum (16/22 courses) and in electives (6/22 courses) that students chose to deepen their knowledge 


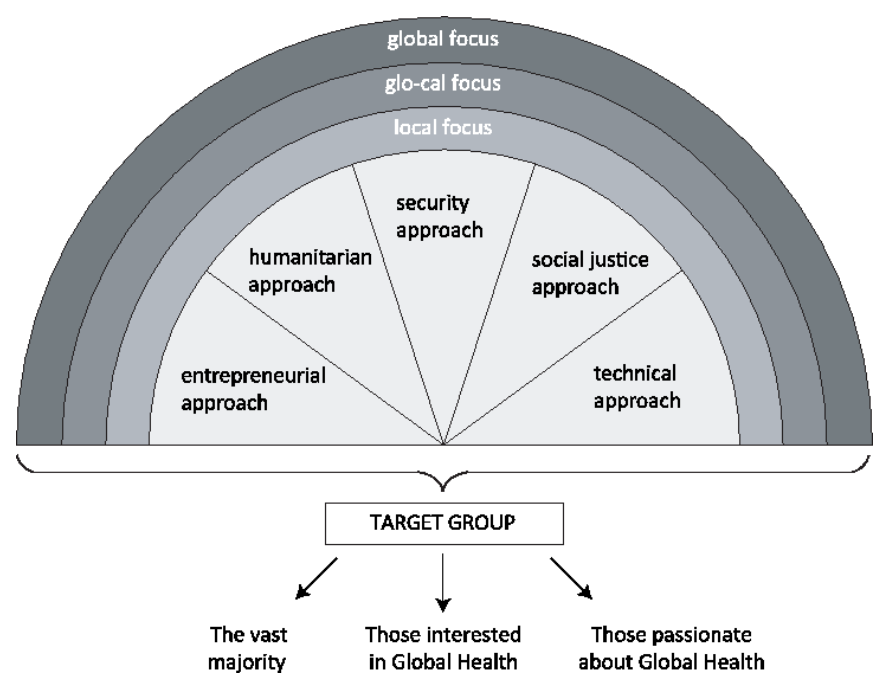

Figure 1 Analytical framework (adapted from Cole et al, ${ }^{18}$ Labonté and Gagnon ${ }^{10}$ and Havemann and Bösner. ${ }^{15}$

according to their interests during their second and third years of study. While classes belonging to the core curriculum include between 1 and 3 teaching units (TU), elective classes are more intensive and comprise between 26 and $60 \mathrm{TU}$. Teaching formats include lectures, seminars and scientific miniprojects complemented by extracurricular activities such as summer schools, intercultural training and panel discussions (figure 2).

For further analysis of the existing curriculum, we categorised the global health classes of our core curriculum according to their approach and focus based on the course descriptions. Our analysis shows that four out of five approaches are represented in our core curriculum. The most frequent one is the technical approach $(10 / 24$
TU), followed by the social justice approach (7/24 TU) and the security approach $(6 / 24 \mathrm{TU})$. The humanitarian approach is present only in one TU. Entrepreneurial aspects are not represented. Local and global foci are evenly distributed in our curriculum (table 1). While in the majority of classes, global and local aspects are taken into consideration, less than half of the classes focus on Germany alone.

Interestingly, all courses dealing with migration have a local perspective while migration at a glo-cal or global scale remains unmentioned. In addition, courses addressing theoretical concepts of globalisation are missing. While elective courses in the second year introduce students more broadly into the field of global health, courses in the third year have a variety of foci and reflect different global health approaches. The course in tropical medicine reflects the classical disease centred approach whereas emergency and disaster medicine addresses primarily problem solving competencies regarding disaster management in different settings. Lastly, the course on primary healthcare encompasses much broader perspectives.

\section{LESSONS LEARNED FROM THE ANALYSIS}

At Charité, we developed our global health curriculum without any predefined reference system. At the pyramid's base, the essential curriculum addresses all students; the middle part provides for students with a particular interest in global health while the top of the pyramid represents specialist perspectives for students seeking for a career in global health (figure 2). The top of the pyramid in this model can only be addressed in specialist postgraduate studies that still need to be
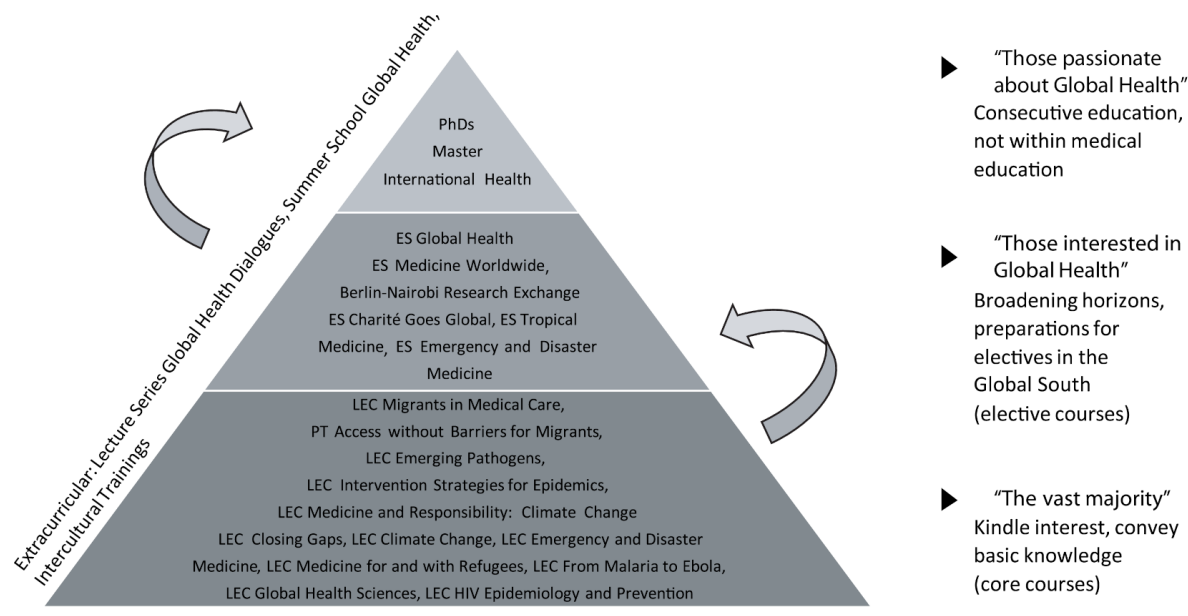

$\mathrm{LEC}=$ lecture, $\mathrm{PT}=$ practical training, $\mathrm{ES}=$ elective semina

Involved institutions/entities: Department for Psychiatry and Psychotherapy (CCM), Department for Gynaecology and Centre for Oncologic Surgery (CVK), Institute of Medical Sociology and Rehabilitation Science, Department of Virology, Institute of Microbiology, Infectious Diseases and Immunology, Institute for Social Medicine, Epidemiology and Health Economics, Department of Infectiology and Pneumonology, Institute of General Practice, Institute of Public Health, Institute of Tropical Medicine and International Health, Department of Anesthesiology and Operative Intensive Care

Medicine (CBF) , Department of Orthopedics and Trauma Surgery, Charité International Cooperation,

Global Health student group, International Physicians for the Prevention of Nuclear War - student group

Figure 2 Global Health learning opportunities at Charité (adapted from Havemann and Bösner). ${ }^{15}$ 
Table 1 Global Health course offers within the medical curriculum at Charité

\begin{tabular}{|c|c|c|c|c|}
\hline Global Health course offers & $\begin{array}{l}\text { Teaching } \\
\text { units }\end{array}$ & Approach & $\begin{array}{l}\text { Focal } \\
\text { point }\end{array}$ & $\begin{array}{l}\text { Target } \\
\text { group }\end{array}$ \\
\hline \multicolumn{5}{|l|}{ Elective classes } \\
\hline $\begin{array}{l}\text { ES-Charité goes global-primary healthcare, global health and infectious diseases } \\
\text { (M24) }\end{array}$ & 60 & All & All & $\mathrm{B}$ \\
\hline ES-Emergency and Disaster Medicine (M24) & 60 & All & All & B \\
\hline ES-Tropical Medicine (M24) & 60 & All & All & $\mathrm{B}$ \\
\hline ES-Global Health-medical profession in globalising times & 26 & All & All & B \\
\hline ES-Medicine: worldwide perspectives and limitations & 26 & All & All & $\mathrm{B}$ \\
\hline EMSR-Berlin-Nairobi exchange program (M 23) & 33 & All & All & B \\
\hline \multicolumn{5}{|l|}{ Core classes } \\
\hline LEC migrants in medical care (M6) & 2 & TEC & Local & C \\
\hline LEC medicine and responsibility: climate change & 1 & TEC & Glo-cal & C \\
\hline LEC intervention strategies for epidemic diseases (M18) & 2 & SEC & Local & C \\
\hline LEC emerging pathogens (M18) & 2 & SEC & Glo-cal & $\mathrm{C}$ \\
\hline LEC HIV/AIDS: epidemiology and prevention (globally and regionally) (M35) & 2 & TEC & Glo-cal & C \\
\hline MSL LEC-How do global health sciences work? & 2 & SJ & Global & C \\
\hline $\begin{array}{l}\text { MSL LEC-closing gaps - primary healthcare and access to medicines in Global } \\
\text { Health (Part 1) }\end{array}$ & 1 & TEC & Glo-cal & C \\
\hline $\begin{array}{l}\text { MSL LEC-closing gaps - primary healthcare and access to medicines in Global } \\
\text { Health (Part 2) }\end{array}$ & 1 & SJ & Glo-cal & C \\
\hline $\begin{array}{l}\text { MSL LEC-climate change-impacts on population health and intervention } \\
\text { strategies }\end{array}$ & 2 & TEC & Global & C \\
\hline MSL LEC-emergency and disaster medicine-local and global help (part 1) & 1 & SEC & Glo-cal & C \\
\hline MSL LEC-emergency and disaster medicine-local and global help (part 2) & 1 & SEC & Local & C \\
\hline MSL LEC-medicine for and with refugees (part 1) & 1 & HUM & Local & C \\
\hline MSL LEC-medicine for and with refugees (part 2) & 1 & SJ & Local & C \\
\hline MSL LEC - from malaria to ebola: infection and epidemic control worldwide (part 1) & 1 & TEC & Global & C \\
\hline MSL LEC - from malaria to ebola: infection and epidemic control worldwide (part 2) & 1 & TEC & Glo-cal & C \\
\hline PT access to healthcare without barriers for migrants (M6) & 3 & SJ & Local & C \\
\hline
\end{tabular}

Teaching unit: 1 teaching unit = $45 \mathrm{~min}, \mathrm{~A}=$ "The passionate about Global Health", B = "Those interested in Global Health", $\mathrm{C}=$ "The vast majority".

EMSR, Elective module scientific research ; ENT, entrepreneurial approach; ES, elective seminar; HUM, humanitarian approach; LEC, lecture; MSL, module supporting lectures; PT, practical training; SEC, security approach; SJ, social justice approach; TEC, technical approach.

developed at Charité. Furthermore, the analysis shows that in core curricular courses local and global foci are equally incorporated, however, there is a clear predominance of technical approaches, while the humanitarian approach is underrepresented, and the entrepreneurial approach is lacking. Consequently, the aim of conveying all approaches to global health in our core curriculum could only partly be achieved.

When comparing our results with the analysis of Labonté and Gagnon ${ }^{10}$ and Cole et $a l^{18}$ the technical approach seems equally dominant, conversely, the entrepreneurial approach which is of greater importance in their analysis does not play a major role for global health education at Charité. Nevertheless, it should be borne in mind that we operated with an all-inclusive umbrella concept of global health, not with an operationalised working definition of what global health represents.
Therefore, our analysis might be biased in the sense that it included classes which in other settings with strict definitions would perhaps be excluded.

The use of such an analytical framework provides three major benefits. First, it allows teachers to recognise, reflect, and sharpen their own priorities in teaching global health. This means that multiple perspectives on certain topics become explicit for teachers and students alike, which helps students to develop informed positions. Implementation of the framework could be fostered by clarifying individual and institutional approaches in a standardised fashion, comparable with a competing interest's statement. Second, such a framework may help to structure global health contents to be taught ex ante, especially when global health topics are to be integrated into an existing curriculum. By making both strengths and weaknesses in the curriculum visible, our framework 
could help to professionalise cross-sectional and interdisciplinary education. Third, our framework may simplify the identification of content that need to be prioritised in order to grant an even representation of approaches and foci in the curriculum. Further, the framework can promote a more coherent global health strategy within an academic setting, by sharpening research priorities, incentives and strategic partnerships. While the analysis with the framework was straightforward, implementing changes according to the results of our analysis requires awareness among all partners.

Global health addresses special health issues, which cannot be fulfilled by curricula for public or international health alone. ${ }^{20}$ To advance global health curricula at medical schools, more knowledge and broader competencies are needed among all health professionals. We contend that teaching global health topics at medical schools is urgently needed across the globe because of the mere fact of rapidly progressing globalisation in all spheres. In this sense, the current COVID-19-pandemic only exacerbates existing local, glo-cal, and global health problems. To face such challenges, interdisciplinarily trained health professionals are desperately needed, better sooner than later. To this end, quick efforts should be made to align the work of politicians and functionaries of global health with the demands of those health professionals who practice global health in the more medical sense. To achieve such an alignment appropriate education in global health is not a choice but an obligation for politicians and health professionals alike. And maybe, it is less a question of just 'more money' to be invested in medical schools, but rather of intelligent management of resources to shape how future health professionals are trained in global health. So far, no unanimous educational model has emerged in the German or international academic landscape so that each medical school has the burden of developing its own approach depending on local partners and financial resources.

Every medical school has its local strengths, intellectual foci, and logistics according to which curricula can be designed in unison with the principles of academic freedom. What our analytical framework for global health can provide is a tool which assesses horizontally the diversity and vertically the depth of a given global health curriculum; further it may also help for a systematic approach to develop a more standardised global health curriculum. Thus, the framework can be used as a tool to analyse global health content in a health curriculum and to guide the development and adaptation of global health curricula. It should also be borne in mind that the German government certainly is not the only driving force behind the efforts to implement global health in German medical schools. Some medical schools are developing global health curricula independent from the governmental push. In addition, bottom-up initiatives such as by the Global Health Alliance Deutschland ${ }^{21}$ and the German Medical Students Association ${ }^{22}$ have been instrumental in fostering global health education.
A major limitation of this analytical framework, as presented above is that it mostly addresses educational perspectives of high and upper middle-income countries, but not necessarily those of the global South. Although global health is supposed to be a global, multilateral, and reciprocal enterprise, and is being promoted as such, perceptions, approaches, and interpretations vary and carry the risk of consolidating asymmetrical power relations. ${ }^{23}{ }^{24}$ Further, despite our attempts to include holistic global health objectives, our framework may contain inherent biases where normative dimensions are overshadowed.

\section{CONCLUSIONS}

For Germany to attain the desired leadership role in global health expressed by the German government and other internationally operating institutions, multipronged efforts are needed to create an appropriate intellectual base in German academia. What is needed first, together with a high degree of sensibility regarding historical influences from past colonial times and National Socialism, is to develop an intellectual model that supports German medical schools to develop their own global health curricula. Such an intellectual model should imply more than just a list of global health related topics to be taught. Education in global health deserves a metalevel of reflection that we have tried to achieve with our proposed analytical framework.

Twitter Angela Schuster @a_mariaschuster

Acknowledgements Many thanks to Remco Van de Pas for continuous support and advice and for offering the opportunity to discuss and develop the research idea with Ronald Labonté, Anja Krumeich and many others in a research colloquium at the Maastricht Centre for Global Health. Further, the authors would like to thank the round table on global health education at Charite for advice and suggestions.We acknowledge support from the German Research Foundation (DFG) and the Open Access Publication Funds of Charité - Universitätsmedizin Berlin.

Contributors AS: conceptualisation, data curation, data analysis, methodology, visualisation, writing of original draft. PG: conceptualisation, methodology, writing-review and editing. NA: conceptualisation, writing-review and editing. $\mathrm{CH}$ : project administration, project funding, conceptualisation, resources, supervision, writing — review and editing.

Funding AS has developed and written the article within her professional commitment at the Institute of General Practice at Charité-Universitätsmedizin Berlin. Publication costs have been covered with support from the German Reserach Foundation (DFG) and the Open Access Publication Funds of CharitéUniversitätsmedizin Berlin

Competing interests The authors of this paper were stakeholders in integrating global health contents into the existing medical curriculum at Charité or supported the process intrinsically through special affiliation with the World Health Summit and Charite Global Health (N.A.). AS is a member of the Global Health Alliance Deutschland.

Patient consent for publication Not required.

Provenance and peer review Not commissioned; externally peer reviewed.

Data availability statement Data are available upon request.

Open access This is an open access article distributed in accordance with the Creative Commons Attribution Non Commercial (CC BY-NC 4.0) license, which permits others to distribute, remix, adapt, build upon this work non-commercially, and license their derivative works on different terms, provided the original work is properly cited, appropriate credit is given, any changes made indicated, and the use is non-commercial. See: http://creativecommons.org/licenses/by-nc/4.0/. 
ORCID iD

Angela Schuster http://orcid.org/0000-0002-4691-3177

\section{REFERENCES}

1 Kickbusch I, Farrar J, Challis M. A new global health strategy for Germany. BMJ 2019;366:14662.

2 Ein neuer Aufbruch für Europa, Eine neue Dynamik für Deutschland, Ein neuer Zusammenhalt für unser Land - Koalitionsvertrag zwischen CDU, CSU und SPD 2018:102.

3 Kaffes I, Moser F, Pham M, et al. Global health education in Germany: an analysis of current capacity, needs and barriers. BMC Med Educ 2016;16:304

4 Macfarlane SB, Jacobs M, Kaaya EE. In the name of global health: trends in academic institutions. J Public Health Policy 2008;29:383-401.

5 Rowson M, Smith A, Hughes R, et al. The evolution of global health teaching in undergraduate medical curricula. Global Health 2012;8:35

6 Khan OA, Guerrant R, Sanders J, et al. Global health education in U.S. medical schools. BMC Med Educ 2013;13:3.

7 Johnson O, Bailey SL, Willott C, et al. Global health learning outcomes for medical students in the UK. Lancet 2012;379:2033-5.

8 Eaton DM, Redmond A, Bax N. Training healthcare professionals for the future: internationalism and effective inclusion of global health training. Med Teach 2011;33:562-9.

9 Knipper M, Baumann A, Hofstetter C, et al. Internationalizing Medical Education: The Special Track Curriculum 'Global Health' at Justus Liebig University Giessen. GMS Z Med Ausbild 2015;32:Doc52.

10 Labonté R, Gagnon ML. Framing health and foreign policy: lessons for global health diplomacy. Global Health 2010;6:14

11 Koplan JP, Bond TC, Merson MH, et al. Towards a common definition of global health. Lancet 2009;373:1993-5

12 Peluso MJ, van Schalkwyk S, Kellett A, et al. Reframing undergraduate medical education in global health: rationale and key principles from the Bellagio global health education initiative. Med Teach 2017;39:639-45.

13 Jogerst K, Callender B, Adams V, et al. Identifying interprofessiona global health competencies for 21st-century health professionals. Ann Glob Health 2015;81:239-47.

14 Bozorgmehr K, Saint VA, Tinnemann P. The 'global health' education framework: a conceptual guide for monitoring, evaluation and practice. Global Health 2011;7:8.

15 Havemann M, Bösner S. Global Health as "umbrella term" - a qualitative study among Global Health teachers in German medical education. Global Health 2018;14:32.

16 Bachrach $\mathrm{S}$. In the name of public health--Nazi racial hygiene. $N$ Engl J Med 2004;351:417-20.

17 Razum O, Vázquez ML. Strengthening public health in Germany: overcoming the Nazi legacy and Bismarck's aftermaths. Int J Public Health 2017;62:959-60.

18 Cole DC, Jackson S, Forman L. What approaches can schools of public health take to engage in global health? reflections on the implications of a conceptual synthesis. Global Health Governance 2017; XI

19 Labonté R. Global health in public policy: finding the right frame? Crit Public Health 2008;18:467-82.

20 Rosso A, Civitelli G, Marceca M. Global health, international health and public health: which relationship? Ann Ig 2012;24:263-7.

21 Geffert K, Hagedorn C, Havemann M, et al. Ein Netzwerk für Lernende und Lehrende Im Bereich Globaler Gesundheit. Das Gesundheitswesen 2018;02:91

22 German-Medical-Students-Association. Positionspapier: Das globale Gesundheitspolitikkonzept Der Bundesregierung, 2014. Available: https://www.bvmd.de/unsere-arbeit/interessenvertretung/ positionspapiere/

23 Nafade V, Sen P, Pai M. Global health journals need to address equity, diversity and inclusion. BMJ Glob Health 2019;4:e002018.

24 Abimbola S. The foreign gaze: authorship in academic global health. BMJ Glob Health 2019;4:e002068. 